\title{
The Big Five Social System Traits as the Source of Personality Traits, MBTI, Social Styles, Personality Disorders, and Cultures
}

\author{
Dingyu Chung \\ Utica, Michigan, USA \\ Email:dy_chung@yahoo.com
}

How to cite this paper: Chung, D. (2017) The Big Five Social System Traits as the Source of Personality Traits, MBTI, Social Styles, Personality Disorders, and Cultures. Open Journal of Social Sciences, 5, 269-295. https://doi.org/10.4236/jss.2017.59019

Received: August 24, 2017

Accepted: September 23, 2017

Published: September 26, 2017

Copyright $\odot 2017$ by author and Scientific Research Publishing Inc. This work is licensed under the Creative Commons Attribution International License (CC BY 4.0).

http://creativecommons.org/licenses/by/4.0/ (c) (i) Open Access

\begin{abstract}
This paper proposes the big five social system traits as the fixed, clear, and workable social solutions to the social issues under the different social conditions. Under the big five social system traits, different fixed and clear personal behaviors are developed by different people under different social conditions, so the big five social system traits are the source of different aspects of human behavior in terms of personality traits in the big five personality traits, personality types in the MBTI, social styles in the social style model, personality disorders in the DSM-5, social group deviances derived from the DSM-5, and religious, political, and economic systems in Western and Eastern cultures as described in this paper. The big five social system traits consist of sociality (individualistic-collectivistic-interdependent) traits to the issue of social formation, worldview traits (connective-competitive-territorial or people-tasks) to the issue of social boundary, awareness traits (concrete-imaginary) to the issue of social stress, activity traits (constructional-mobilized) to the issue of social duration, and legitimacy traits (authoritative-rational) to the issue of social uniformity. As a result, the big five social system traits provide the base for the unified theory of human behavior to unify different aspects of human behavior and to produce the common ground for diverse views to communicate.
\end{abstract}

\section{Keywords}

Big Five Social System Traits, Big Five Personality Traits, MBTI, Social Style Model, Personality Disorders, DSM-5, Western Culture, Eastern Culture, Social Group Deviances, Unified Theory of Human Behavior

\section{Introduction}

According to Talcott Parsons [1] who was the first to formulate the concept of 
social system in modern sociology, social system is an orderly arrangement of interrelated parts. A social system consists of a number of interrelated parts which face a number of different social issues, such as social formation, social boundary, social stress, social duration, and social uniformity. Each social issue is under different social conditions, such as allies or friends, ingroup or outgroup, stressful or stress-free social system, transient or longevous social system, and homogenous or pluralistic social system. Under different social conditions, different issue have different fixed, clear, and workable fixed social solution as social system traits, such as sociality (degree of social formation) [2], worldview [3], awareness [3], activity, and legitimacy [4]. Social system traits are the fixed, clear, and workable social solutions to the issues of social systems under the different conditions of social systems.

For examples, in some social animals, the males, such as male chimpanzees, live under the social condition of allies with changeable social bonds among the males, so the social system trait as the fixed, clear, and workable solution to the issue of social formation under the social condition of allies with changeable social bonds is individualistic sociality where each individual takes care of itself. The females, such as female bonobos, on the other hand, live under the social condition of friends with strong social bonds among the female friends, so the fixed, clear, and workable social solution as social system trait to the issue of social formation under the social condition of friends with strong social bonds is collectivistic sociality where each individual belongs to a social group. This paper proposes the five social system traits consisting of sociality, worldview, awareness, activity, and legitimacy [2] [3] [4].

Under the big five social system traits, different fixed and clear personal behaviors are developed by different people under different social conditions, producing different fixed and clear personality traits for different people. For examples in great apes, individualistic sociality social system trait produces the personality trait of extraversion that pays relentless and forcible attention to changeable social bonds of allies as shown in the active extravert behavior of individualistic adult male chimpanzees among the males [5]. Collectivistic sociality social system trait produces the personality trait of introversion that pays timely and moderate attention to stable social bonds of friends as shown in the mild introvert behavior of collectivistic adult female bonobos among the females. Therefore, social system traits are the source of personality traits as the fixed and clear personal solutions to the issues of social systems under the different conditions of social systems. Not all aspects of personality traits are workable in social system which is fixed, clear, and workable. Only positivized aspects of personality trait lead to social system. The extremely negative aspects of personality traits lead to personality disorders.

An important model for human personality traits is the big five personality traits consisting of extraversion (assertive, energetic, talkative), agreeableness (cooperative, good-natured, trusting), neuroticism (easily upset, maladjusted, 
not calm), conscientiousness (dependable, orderly, responsible), and openness to experience (imaginative, independent-minded, intellectual) [6]. The opposites are introversion, disagreeableness, calmness, impulsiveness, and closeness to experience. This paper proposes that the big five personality traits are derived from the big five social system traits. This paper proposes that the big five social system traits also produce personality types in the MBTI (Myers-Briggs Type Indicator) [7], social styles in the social style model [8], personality disorders in the DSM-5 (the Diagnostic and Statistical Manual of Mental Disorders, Fifth Edition) [9] [10] and cultures (religious, political, and economic systems) [4]. Section 2 describes the big five social system traits which produce the big five personality traits, the MBTI, the social style model, and personality disorders. Section 3 describes religious, political, and economic systems derived from the big five social system traits.

\section{Big Five Social System Traits, Personality Traits, MBTI, Social Styles, and Personality Disorders}

This section proposes the big five social system traits as the fixed, clear, and workable social solutions to the issues of social systems under the different conditions of social systems. Under the big five social system traits, different fixed and clear personal behaviors are developed by different people under different social conditions, so the big five social system traits are the source of different aspect of human behavior in terms of personality traits in the big five personality traits, personality types in the MBTI, social styles in the social style model, and personality disorders in the DSM-5 as described in this section. The first part of this section describes the big five social system traits and the derivation of the big five personality traits from the big five social system traits. The second part of this section describes the big five social system traits, the MBTI, and the social style model, and the third part of this section describes the big five social system traits and personality disorders.

\subsection{The Big Five Social System Traits and the Big Five Personality Traits}

In this subsection, the five social issues consisting of social formation, social boundary, social stress, social duration, and social uniformity produce the big five social system traits, consisting of sociality [2], worldview [3], awareness [3], activity, and legitimacy [4], respectively. The big five social system traits produce the big five personality traits as in Table 1 and as follows.

\subsubsection{Sociality Social System Traits and Extraversion-Introversion Personality Traits}

The issue of sociality social system traits is the degree of social formation [2]. The conditions of sociality are the relationships of allies, friends, and intimates. The relationship among allies is changeable based on the individual's benefit that can be obtained from the relationship of allies. Each individual in allies has to 
Table 1 . The big five social system traits and the big five personality traits.

\begin{tabular}{cccc}
\hline Issues & Conditions & Social System Traits & Personality Traits \\
\hline 1) sociality & allies & individualistic sociality & extraversion \\
& friends & collectivistic sociality \\
intimates & interdependent sociality & (introversion) \\
& ingroup & connective worldview & agreeableness \\
2) boundary & outgroup & competition worldview & (disagreeableness) \\
& ingroup-outgroup & territorial worldview & (isolation) \\
3) stress & stress-free & concrete awareness & (calmness) \\
& stress & imaginary awareness & neuroticism \\
4) duration & transience & mobilized activity & (impulsiveness) \\
& longevity & constructional activity & conscientiousness \\
5) legitimacy & homogeneity & authoritative legitimacy & (closeness to experience) \\
& pluralism & rational legitimacy & openness to experience \\
\hline
\end{tabular}

take care of itself for its own benefit. The social system trait as the fixed, clear, and workable solution to the issue of social formation under the condition of the relationship of allies is individualistic sociality. For example, for the great apes, each male adult chimpanzee under the relationship of allies has to fight for his food and social ranking without belonging to any specific stable social group. As a result, male adult chimpanzee has the social system trait of individualistic sociality. The goal of individualistic sociality is individualistic achievement.

The relationship of friends and kin is stable based on the dependence of individual's wellbeing on a social group. The social system trait to the issue of social formation under the condition of the relationship of friends and kin is collectivistic sociality. The origin of collectivistic sociality is the social group of caregivers and vulnerable children. To continue the genes from generation to generation, the original collectivistic sociality is necessary to protect vulnerable children who are genetically related. The social group consisting of children and caregivers is kin group as described by inclusive fitness [2] [11] of kin selection based on the Hamilton's Rule. For example, for the great apes, the sociality of orangutan, gorillas and bonobos is collectivistic sociality under the relationships of kin and friends. The goal of collectivistic sociality is collectivistic wellbeing.

The relationship of intimates is very stable based on existential interdependence among intimates. The social system trait to the issue of social formation under the condition of the relationship of intimates is interdependent sociality. The origin of interdependent sociality involves vulnerable social group which cannot survive without existential interdependence in the form of division of labor by the adults. For example, to survive as a social group, bees must undergo division of labor, because queen bees must rely on workers bees to feed them, and infertile worker bees must rely on queen bees to reproduce. The interdependent fertile queen bee, fertile drone bee, and infertile worker bee work interdependently to assure the survival of social group. Such interdependence based on division of labor of interdependent individuals for the survival of social group 
is analogous to the interdependence based on division of labor of interdependent body parts for the survival of the whole body. Interdependent sociality is eusociality [12] existed in bees, termites, and ants. Human is eusocial [13], consisting of the interdependent fertile homemaker-gatherer, infertile homemaker-gatherer, and fertile explorer-hunter during the evolution of humans [2]. The goal of interdependent sociality is the survival of the social group.

In the big five personality traits, extraversion as relentless and forceful attention to relationship is derived from individualistic sociality in the social system of allies with changeable social bonds, while introversion as timely and moderate attention to relationship results from collectivistic sociality and interdependent sociality from the social systems of friends and intimates with stable social bonds. For examples, extraversion that pays relentless and forcible attention to changeable social bonds of allies is shown in individualistic adult male chimpanzees among the males, while introversion that pays timely and moderate attention to stable social bonds of friends is shown in collectivistic adult female bonobos among the females. In the study of personality profiles of cultures, individualism is correlated to extraversion [14]. Introversion should not be confused with shyness. Shy people find it very difficult to socialize while introverts enjoy people. Introverts simply do not seek relentlessly and forcibly to be the center of attention.

\subsubsection{Worldview Social System Traits and} Agreeableness-Disagreeableness-Isolation Personality Traits

The issue of worldview social system traits is the boundary of social system [3] [4]. All advanced social animals have boundary in terms of ingroup and outgroup. In ingroup, individuals share similar interests and attitudes, and produce instinctive feeling of ingroup favoritism as solidarity, community, and exclusivity [15]. Individuals in outgroup outside one's own group are different in interests and attitudes, and produce instinctive feeling of outgroup derogation as inferiority and alienation. Morality is defined as proper behavior. Morality toward ingroup is opposite of morality toward outgroup [16]. Ingroup morality is cooperative connection derived from instinctive ingroup favoritism. Outgroup morality is zero-sum aggressive competition derived from mutual outgroup derogation among social groups. According to evolutionary psychologists, this discrimination between connective ingroup morality and competitive outgroup morality has evolved because it enhances group survival in terms of instinctive cooperative connection toward ingroup and instinctive aggressive competition toward outgroup [17].

Under a clear boundary with a large buffer zone between ingroup and outgroup, the worldview social system trait is territorial worldview. Without a clear boundary with a large buffer zone, the worldview can be connective worldview to view the world mostly as ingroup or competitive worldview to view the world mainly as outgroup. For examples [3] [4], the great apes with territorial worldview are orangutan, gorilla, and prehistoric human. Chimpanzees and bonobos live in 
fission-fusion society with overlapping social groups, so the boundary between ingroup and outgroup is not clear. As a result, chimpanzee has competitive worldview in the competitive environment without abundant resource, and bonobo has connective worldview in the non-competitive environment with abundant resource. To combine individualistic sociality and competitive worldview, adult male chimpanzees is individualistic-competitive as highly aggressive individualistic warriors [5], while adult female bonobos is collectivistic-connective as highly friendly collectivistic peacemakers. Agreeableness, disagreeableness, and isolation in personality traits are derived from connective, zero-sum competitive, and territorial worldviews, respectively from the social systems of ingroup, outgroup, and ingroup-outgroup, respectively.

\subsubsection{Awareness Social System Traits and Neuroticism-Calmness Personality Traits}

The issue of awareness social system traits is the stress of social system. Stress affects significantly animals' behaviors. For humans, stress causes permanent imaginary awareness. Imaginary awareness in terms of religion became an important part of human society during the Upper Paleolithic Period about 40,000 years ago [3]. During the period from the beginning of Homo sapiens around 200,000 years ago to 40,000 years ago before the Upper Paleolithic Period, there was no evidence for extensive and significant religious practice with imaginary awareness. The Upper Paleolithic Period was a very difficult cold period that prompted vulnerable humans to turn to the imaginary supernatural for the survival. The imaginary supernatural was represented by the imaginary well-nourished and fertile female figurines with the accent on female breasts and the posterior [18] and the imaginary cave paintings with imaginary vital and powerful animals [19]. To help people to survive the harsh time and to change the fate facing grim winters and a scarce food supply, the female figurines symbolized and brought the hope for a well-nourished and fertile community, and the cave paintings symbolized and brought the hope for a vital and powerful community. During this harsh time, Neanderthals who were remarkably similar to humans became extinct, because Neanderthals required about 600 or 700 calories a day more than humans to survive [20], and probably also because Neanderthals did not develop such imaginary religious symbols to help them to survive the harsh time. Maurice Bloch [21] proposes that religion was derived from the development of imagination occurred at about the time of the Upper Paleolithic Period. Since then, religion as imaginary awareness has become the integral part of human society. For humans, the awareness social system trait to the issue of stress under the condition of stress is imaginary awareness, while the awareness social system trait under stress-free condition is concrete awareness.

Imaginary awareness in terms of imaginary companions is common among children. Up to two-thirds of children have imaginary companions [22]. Some children develop entire imaginary worlds for their imaginary companions. Most

of these children are not lonely or have social problems. Imaginary companions 
are an integral part of many children's lives, provide comfort in times of stress, and help them to overcome traumatic experiences [23]. It is inevitable that permanent imaginary awareness in terms of religion becomes an integral part of human society. Imaginary awareness is derived from instinctive "theory of mind". Theory of mind is to recognize (imagine) that the others exist to think for themselves. In other words, you imagine thinking like another person. Autistic individuals with problems in imaginative capacities are incapable of theory of mind [24]. The practical purposes of imagination are to imagine you thinking like another person to detect cheatings by the person. With robust theory of mind, only humans have imaginary awareness. Workable imaginary awareness overcomes stressful-traumatic experiences.

In the big five personality traits, neuroticism is derived from imaginary awareness in stressful social system that generates permanent imaginary thoughts, while calmness results from concrete awareness in stress-free social system that generates concrete thoughts. Neuroticism generates imaginary thoughts with mostly negative effects which are unworkable in orderly social system. Only the positivized imaginary awareness is the foundation of functional and beneficial religion. The extremely negative aspects of imaginary awareness lead to personality disorders.

\subsubsection{Activity Social System Traits and Conscientiousness-Impulsiveness Personality Traits}

The issue of activity social system traits is the duration of social system which has two different conditions: transient social system and longevous social system. In human social system, transient social system results from the perceived possible end of a social system by natural destruction-renewal or by dramatic downfall-rise. The perceived possible end of social system causes mobilized activity such as heroism. Every social system prepares people to mobilize in the case of natural destruction-renewal or dramatic downfall-rise, so heroism and martyrdom are often glorified. Without the perceived possible end of social system, the activity is constructional activity which is deliberated and protracted for longevous social system. The activity social system trait to the issue of the duration of social system under the condition of transience is mobilized activity, while the activity social system trait under the condition of longevity is constructional activity as the deliberated and protracted activity for longevous social system. Mobilized activity is derived from the hyperactivity of instinctive fight-or-flight response as the physiological reaction in response to perceived possible end of life by a harmful event, attack or threat to survival. It exists in all advanced social animals. Workable mobilized activity prevents downfall.

In the big five personality traits, conscientiousness as broad deliberation is derived from constructional activity in longevous social system, while impulsiveness as narrow deliberation results from mobilized activity in transient social system. Impulsiveness mostly is unworkable for orderly social system, but positivized impulsiveness leads to workable mobilized activity for transient social 
system. The extremely negative aspects of impulsiveness lead to personality disorders.

\subsubsection{Legitimacy Social System Traits and Openness-Closeness to Experience Personality Traits}

The issue of legitimacy social system traits in terms of the justification of valid social system is social uniformity under the conditions of homogeneity and pluralism [4]. In homogeneous social system, typically, authoritative legitimacy legitimizes social system through authoritative tradition without questioning the legitimacy of authoritative tradition. On the other hand, in pluralistic social system with conflicting well-established traditions, authoritative legitimacy cannot be followed. All conflicting well-established traditions must be questioned in pluralistic social system, resulting in chaos to reject authoritative legitimacy. Human capacity of reasoning in the frontal lobe of the neocortex for the rational brain allows human society to develop workable rational system as a provable, logical, consistent, demonstrable, and factual system to replace authoritative system and unworkable chaos. The legitimacy social system trait to the issue of social uniformity under the condition of homogeneity is authoritative legitimacy, while the legitimacy social system trait under the condition of pluralism is rational legitimacy. Authoritative legitimacy is derived from the instinctive fear toward unfamiliarity and unreliability, and such fear forces people to follow authoritative tradition and reliable authority. Authoritative legitimacy exists in all advanced social animals. Workable authoritative legitimacy protects familiarity and reliability in tradition. With the robust rational brain, only humans have workable rational legitimacy which is provable, logical, consistent, demonstrable, and factual. Workable rational legitimacy provides consistency and transparency in diverse system.

In the big five personality traits, openness to experience to question all traditions is derived from rational legitimacy to accommodate diverse pluralistic social system, while closeness to experience to obey all traditions results from authoritative legitimacy to accommodate uniform homogeneous social system. The positivized openness to experience leads to workable rational legitimacy, while the positivized closeness to experience brings about workable authoritative legitimacy. The extremely negative aspects lead to personality disorders.

\subsection{The Big Five Social System Traits, the MBTI, and the Social Style Model}

In this subsection, the personality models, including the big five personality traits, the four dimensional MBTI (extraversion-introversion, feeling-thinking, sensing-intuition, and perceiving-judging) [7] and the two dimensional social style model (tell-ask and people-tasks) [8] are derived from the big five social system traits as in Table 2.

Individualistic sociality produces extraversion in the big five personality traits and the MBTI and "tell" (high assertiveness) in the social style model. "Tell" 
Table 2. The comparison of the models.

\begin{tabular}{|c|c|c|c|c|}
\hline Social System Traits & Personality Traits & MBTI & Social Styles & Personality Disorders \\
\hline individualistic sociality & extraversion & & & \\
\hline collectivistic sociality & (introversion) & extraversion & tell & \\
\hline interdependent sociality & (introversion) & introversion & ask & \\
\hline connective worldview & agreeableness & & & \\
\hline or people worldview & agreeableness & feeling & people & \\
\hline competition worldview & (disagreeableness) & & & \\
\hline or tasks worldview & (disagreeableness) & thinking & tasks & \\
\hline territorial worldview & (isolation) & & & \\
\hline concrete awareness & (calmness) & & & odd-eccentric cluster \\
\hline imaginary awareness & neuroticism & & & \\
\hline mobilized activity & (impulsiveness) & perceiving & & dramatic-impulsive cluster \\
\hline constructional activity & conscientiousness & judging & & \\
\hline authoritative legitimacy & (closeness to experience) & sensing & & anxious-fearful cluster \\
\hline rational legitimacy & openness to experience & intuition (new) & & (doubtful-prying cluster) \\
\hline
\end{tabular}

indicates the center of attention as the high assertive behavior of extraverts. Collectivistic sociality and interdependent sociality produce introversion in the big five personality traits and the MBTI and "ask" in the social style model. "Ask" (low assertiveness) indicates outside of the center of attention as the low assertive behavior of introverts.

Worldview as a particular view of the world can deal with people only or people-tasks. Ingroup and outgroup can be people in ingroup and people in outgroup as connective worldview and competitive worldview. On the other hand, ingroup and outgroup can be people in ingroup and tasks in outgroup because tasks are not people, resulting in people worldview and tasks worldview. To deal with people requires mostly feeling, so people worldview produces "feeling" in the MBTI and "people" (high responsiveness) in the social style model. To deal with tasks requires mostly thinking, so tasks worldview produces "thinking" in the MBTI and "tasks" (low responsiveness) in the social style model.

In the MBTI, "judging" prefers to complete organized and structured assignments, while "perceiving" prefers exciting and flexible ideas. Mobilized activity produces impulsiveness in the big five personality traits and perceiving in the MBTI, while constructional activity produces conscientiousness in the big five personality traits and judging in the MBTI. In the MBTI, "sensing" is to sense practical, concrete, and routine details, while "intuition" involves the details other than practical, concrete, and routine details. In general, intuition includes imaginary odd intuition and non-routine new intuition, but the MBTI does not deal with imaginary odd intuition, particularly negative imaginary odd intuition correlating to neuroticism in the big five personality traits, so neuroticism in the big five does not match any type in the MBTI. In the MBTI, intuition is 
non-routine new intuition. Authoritative legitimacy produces closeness to experience in the big five personality traits and sensing in the MBTI, while rational legitimacy produces openness to experience in the big five personality traits and non-routine new intuition in the MBTI. As a result, extraversion, agreeableness, conscientiousness, and openness to experience in the big five personality traits are correlated to extraversion-introversion, thinking-feeling, judging-perceiving, and sensing-intuition, respectively in the MBTI, which is same as the result of the previous correlational analysis between the big five personality traits and the MBTI from a total of 900 participants [25].

\subsection{The Big Five Social System Traits and Personality Disorders}

In this subsection the DSM-5 personality disorders [9] [10] are derived from the big five social system traits as in Table 2. Personality disorders are characterized by enduring maladaptive patterns of behavior, cognition, and inner experience deviating from prevailing cultures. Different prevailing cultures produce different personality disorders. The 10 personality disorders in the DSM-5 are divided into odd-eccentric, dramatic-impulsive, and anxious-fearful clusters [10]. This paper proposes that two different types of personality disorders are the futile personality disorders and recklessness personality disorders. Futile personality disorders are derived from maladaptive personality traits under the extreme confrontations against their opposite social system traits which prevail culturally. In other words, prevailing culture simply considers the extreme confrontation against prevailing culture as the maladaptive behavior of personality disorder, while being different from or modest objection to prevailing culture is not considered as personality disorder. The prevailing social system traits for the current prevailing culture are concrete awareness trait for affluent society, constructional activity for longevous society, and rational legitimacy trait for diverse society. Odd-eccentric cluster derived from maladaptive neuroticism trait is against prevailing concrete awareness trait, dramatic-impulsive cluster derived from maladaptive impulsiveness trait is against prevailing constructional activity trait, and anxious-fearful cluster derived from maladaptive closeness to experience trait is against prevailing rational legitimacy trait. The unmentioned cluster in the DSM-5 is doubtful-prying cluster which is derived from maladaptive openness to experience trait against prevailing authoritative legitimacy trait. Doubtful-prying cluster is not personality disorder in the DSM-5, because rational legitimacy trait allowing doubt-prying prevails in science such as the DSM-5. However, authoritative legitimacy trait forbidding doubt-prying prevails in authoritative Western religions which definitely consider doubt-prying as personality disorder, namely, sin.

Reckless personality disorders are derived from maladaptive personality traits under extremely adverse conditions without their workable social system traits. In this way, the extremely negative aspects of personality traits emerge recklessly as personality disorders without the control of workable social system traits. 
Odd-eccentric cluster is derived from maladaptive neuroticism trait under extreme stress-trauma [26] without workable imaginary awareness trait. Dramatic-impulsive cluster is derived maladaptive impulsiveness trait as extreme hyperactivity [27] under perceived extreme danger of downfall without workable mobilized activity trait. Anxious-fearful cluster is derived from maladaptive closeness to experience trait under perceived extreme danger of unfamiliarity and unreliability without workable authoritative legitimacy trait. Doubtful-prying cluster is derived from maladaptive openness to experience trait under perceived extreme danger of inconsistency and opacity without workable rational legitimacy trait.

Extremely adverse conditions with workable social system traits do not bring about reckless personality disorders, in the sense that workable social system traits overcome reckless personality disorders. Workable imaginary awareness trait overcomes odd-eccentric cluster, workable mobilized activity trait overcomes dramatic-impulsive cluster, workable authoritative legitimacy trait overcomes fearful-anxious cluster, and workable rational legitimacy overcomes doubtful-prying cluster. Therefore, workable social system traits are therapies for personality disorders. Futile personality disorders are milder than reckless personality disorders which do not follow any workable social system traits. Futile personality disorders can turn into reckless personality disorders.

Each of the personality disorders in the three clusters in DSM-5 and doubtful-prying cluster is agreeable maladaptive, disagreeable maladaptive, or isolating maladaptive personality trait as in Table 3.

Agreeable personality disorder is maladaptive, sociable, and inoffensive, disagreeable personality disorder is maladaptive, sociable, and offensive, and isolating personality disorder is maladaptive, unsociable, and inoffensive. In odd-eccentric cluster, schizotypal is agreeable maladaptive neuroticism, paranoid is disagreeable

Table 3. Personality disorders from maladaptive personality traits.

\begin{tabular}{|c|c|c|c|}
\hline Clusters & $\begin{array}{c}\text { Maladaptive Personality } \\
\text { Traits }\end{array}$ & Personality Traits & Personality Disorders \\
\hline odd-eccentric & maladaptive neuroticism & $\begin{array}{l}\text { agreeableness } \\
\text { disagreeableness } \\
\text { isolation }\end{array}$ & $\begin{array}{l}\text { schizotypal } \\
\text { paranoid } \\
\text { schizoid }\end{array}$ \\
\hline dramatic-impulsive & $\begin{array}{l}\text { maladaptive } \\
\text { impulsiveness }\end{array}$ & $\begin{array}{l}\text { agreeableness } \\
\text { disagreeableness } \\
\text { isolation }\end{array}$ & $\begin{array}{l}\text { histrionic } \\
\text { antisocial, borderline } \\
\text { narcissistic }\end{array}$ \\
\hline anxious-fearful & $\begin{array}{l}\text { maladaptive closeness to } \\
\text { experience }\end{array}$ & $\begin{array}{l}\text { agreeableness } \\
\text { disagreeableness } \\
\text { isolation }\end{array}$ & $\begin{array}{l}\text { dependent } \\
\text { obsessive-compulsive } \\
\text { avoidant }\end{array}$ \\
\hline doubtful-prying & $\begin{array}{l}\text { maladaptive openness to } \\
\text { experience }\end{array}$ & $\begin{array}{l}\text { agreeableness } \\
\text { disagreeableness } \\
\text { isolation }\end{array}$ & $\begin{array}{l}\text { anarchic } \\
\text { quarrelsome } \\
\text { evasive }\end{array}$ \\
\hline
\end{tabular}


maladaptive neuroticism, and schizoid is isolating maladaptive neuroticism. In dramatic-impulsive cluster, histrionic is agreeable maladaptive impulsiveness, antisocial and borderline are disagreeable maladaptive impulsiveness, narcissistic is isolating maladaptive impulsiveness. Both antisocial and borderline are disagreeable maladaptive impulsiveness in terms of impulsive aggression. The difference between them is that antisocial is mostly aggression toward others, while borderline is mostly aggression toward self. In anxious-fearful cluster, dependent is agreeable maladaptive closeness to experience, obsessive-compulsive is disagreeable maladaptive closeness to experience, and avoidant is isolating maladaptive closeness to experience. This paper proposes anarchic, quarrelsome, and evasive for doubtful-prying cluster. In doubtful-prying cluster, anarchic is agreeable maladaptive openness to experience, quarrelsome is disagreeable maladaptive openness to experience, and evasive is isolating maladaptive openness to experience. Therefore, all observed personality disorders are theoretically classified neatly.

\section{The Big Five Social System Traits and Religious, Political, and Economic Systems}

Under the big five social system traits, different fixed and clear personal behaviors are developed by different people under different social conditions, so the big five social system traits are the source of human behavior in terms of religious, political, and economic systems in Western and Eastern cultures. This section describes the big five social system traits and cultures. In the first part of this section, the cultures derived from the combination of sociality, worldview, and awareness are divided into competitive Western culture, connective Eastern culture, and territorial local culture. The second part of the section describes the cultures from activity social system traits, and the third part of this section describes the cultures from legitimacy social system traits.

\subsection{The Cultures from the Combination of Sociality, Worldview, and Awareness Social System Traits}

The cultures include religious, political, and economic systems. Religious system has imaginary awareness trait, while political and economic systems have concrete awareness trait, so there are three awareness traits including religious imaginary, political concrete, and economic concrete awareness traits. There are three sociality traits consisting of individualistic, collectivistic, and interdependent sociality traits and three worldview traits composing of competitive, connective, and territorial worldview traits. As a result, the combined sociality-worldviewawareness traits produce 27 social systems as in Table 4.

The Agricultural Revolution (Neolithic Revolution) transformed the hunter-gatherer society to the agricultural-nomad society about 10,000 years ago, resulting in the formation of large social groups as large city states and clans. The merges, splits, and migrations of various large social groups resulted in the transformation of interdependent sociality under interdependent small group of 
Table 4. The combined sociality-worldview-awareness traits for 27 religious, political, and economic systems.

\begin{tabular}{llll}
\hline \multicolumn{1}{c}{ Sociality-Worldview } & \multicolumn{1}{c}{$\begin{array}{c}\text { Religious Systems } \\
\text { (imaginary) }\end{array}$} & \multicolumn{1}{c}{ Political Systems (concrete) } & Economic Systems (concrete) \\
\hline $\begin{array}{l}\text { individualistic competitive } \\
\text { collectivistic competitive } \\
\text { interdependent competitive }\end{array}$ & $\begin{array}{l}\text { Greek individualism, Islam } \\
\text { Judaism, Islam }\end{array}$ & $\begin{array}{l}\text { liberal democracy } \\
\text { political statism } \\
\text { competitive political professionalism }\end{array}$ & $\begin{array}{l}\text { capitalism } \\
\text { economic statism } \\
\text { competitive economic professionalism }\end{array}$ \\
$\begin{array}{l}\text { individualistic connective } \\
\text { collectivistic connective } \\
\text { interdependent connective }\end{array}$ & $\begin{array}{l}\text { Hinduism, Confucianism } \\
\text { Hinduism, Confucianism }\end{array}$ & $\begin{array}{l}\text { individualistic meritocracy } \\
\text { collectivistic meritocracy } \\
\text { connective political professionalism }\end{array}$ & $\begin{array}{l}\text { individualistic connection economy } \\
\text { collectivistic connection economy } \\
\text { connective economic professionalism }\end{array}$ \\
$\begin{array}{l}\text { individualistic territorial } \\
\text { collectivistic territorial } \\
\text { interdependent territorial }\end{array}$ & $\begin{array}{l}\text { local individualistic religion } \\
\text { local collectivistic religion } \\
\text { prehistoric religion }\end{array}$ & $\begin{array}{l}\text { individualistic territorialism } \\
\text { collectivistic territorialism } \\
\text { territorial political professionalism }\end{array}$ & $\begin{array}{l}\text { individualistic protectionism } \\
\text { collectivistic protectionism } \\
\text { territorial economic professionalism }\end{array}$ \\
\hline
\end{tabular}

intimates into individualistic sociality and collectivistic sociality to accommodate large social groups of allies and friends, and produced competitive worldview and connective worldview to accommodate the absence of clear boundary.

As described before [4], agricultural society and nomadic society developed different worldviews. In sedentary agricultural society, the main economic growth model was the economic gain in agricultural products from the investment in the complex infrastructures, such as market, transportation, and irrigation. The infrastructure involves both basic physical and organizational structures-facilities. Agricultural society was motivated to form alliances in order to connect the infrastructures among city-states. As a result, agricultural society developed connective worldview to view the world as connective city-states. In mobile nomadic society without a fixed settlement for the complex infrastructures, the main economic growth model was the economic gain from the plundering of properties by conquest. The plundering of properties by conquest in nomadic society generated the competitive world, so nomadic society developed competitive worldview to view the world consisting of competitive tribes.

Nomadic society was too small to develop great civilization as the four agricultural river valley civilizations in Nile River of Egypt, Tigris-Euphrates Rivers of Iraq, Yellow River of China, and Indus River of India/Pakistan. However, in Western culture, nomadic societies (the Semitic nomads and the Eurasian nomads) conquered agricultural societies (the agricultural Middle Kingdom of Egypt and the agricultural Sumer) to establish competitive worldview, while in Eastern culture, agricultural society maintained connective worldview, and resisted competitive worldview from invaded nomadic society. According to $\mathrm{Mi}$ chael Karlberg, Western culture is essentially the culture of contest [28]. The world contains competitive Western culture originated from the Middle East and Greece, connective Eastern culture originated from India and China, and territorial local culture in various places. 


\subsubsection{Competitive Western Culture}

As described in the previous paper [3], the three most important individualistic-collectivistic competitive religions in the West are Judaism from Israel, Greek individualism from Greece, and Islam from Arab. Greek individualism includes individualistic Greek mythology and Greek philosophy. The Israel tribe was herd-nomadic tribe, Greece with the strong influence from Athenian culture was trade-nomadic society for trading olive oil, and Arab was both herd- and trade-nomadic tribe. Herd-nomadic society required strong collectivistic government to protect a tribe, so herd-nomadic society developed collectivistic competitive trait. Judaism unified 12 herd-nomadic clans to become collectivistic competitive imaginary social system. Trade-nomadic society developed trading cities to trade goods from different places. In a trading city of trade-nomadic society, a high degree of freedom was required among individual traders from many different cultural and political backgrounds to trade and to exchange information freely, so trade-nomadic society developed individualistic competitive imaginary social system. Greek individualism unified trading city states to become individualistic competitive social system. Arab was the mixture of both herd-nomadic society and trade-nomadic society. Islam unified both herd-nomadic and trade-nomadic clans to become individualistic-collectivistic competitive imaginary social system. The interdependent competitive religion in the West is Christianity to return to interdependent sociality practiced in the prehistoric society. Christianity practices the interdependent ways of life in the kingdom of God based on love and the interdependence among the followers of Jesus Christ as described in 1 Corinthians 12:27: "Now you are the body of Christ, and each one of you is a part of it".

For the political systems in the West, the individualistic competitive concrete political system is liberal democracy. Democracy is basically individualistic competition through competitive election system among individuals. Each individual has the freedom to zero-sum compete politically. To avoid chaos, rational legal system is incorporated in liberal democracy. The inherent weakness in liberal democracy is inequality resulted from the control of politics by money regardless of election result [29]. The collectivistic competitive concrete political system is political statism, such as socialism promoting social justice and equality. Socialism has a coherent collectivistic social group based on the ideology of socialism which has zero-sum competition against other ideologies. The inherent weakness of political statism is dissent, and the total suppression of dissent leads to totalitarianism. In large society, each political profession has a specialized skill, and various political professions are interdependent, resulting in competitive political professionalism as the implicit interdependent competitive concrete political system for all competitive political systems.

For the economic systems in the West, the individualistic competitive concrete economic system is capitalism as private free market economy. Capitalism is basically individualistic competition through competitive private free market among individuals. Each individual has the freedom to compete economically. 
To avoid chaos, rational legal system is incorporated in capitalism. The inherited weakness of capitalism is fragmented and fragile private capitals of individuals, leading to occasional economic collapses by over-demand or over-supply. The collectivistic competitive concrete economic system is economic statism in which the state has substantial centralized control over economic affairs. There is no economic individualistic competition in economic statism. The inherited weakness of economic statism is the slow responsiveness of collective group economy, leading to the lack of flexibility and diversity. The interdependent competitive concrete economic system is competitive economic professionalism among interdependent economic professions.

\subsubsection{Connective Eastern Culture}

The two most important individualistic-collectivistic connective religions are Hinduism and Confucianism [4]. The rulers in China and India were mostly agricultural people. Originated from agricultural India, Hinduism is a connective religion with the Vedas among the oldest sacred texts. Originated from agricultural China, Confucianism is a connective religion. Unlike the competitive Western religions, Hinduism and Confucianism do not have zero-sum competition against other religions. Traditionally, China and India practice religious tolerance as long as religions remain peaceful and law-abiding. Connective religions can be individualistic or collectivistic under different environments [30]. The interdependent connective religions in the East are Buddhism and Daoism to return to interdependent sociality practiced in the prehistoric society. Buddhism emphasizes compassion toward all living beings, and recognizes impermanence and interdependence. Daoism practices the interdependent ways of life based on yin-yang interdependence, natural instinct, and the unity with the nature.

For the political systems in the East [4], the individualistic-collectivistic connective concrete political system is individualistic-collectivistic meritocracy. Meritocracy is based on merits (achievements) which are typically measured by education, examination, ethics, experience, and job preformation. Unlike competitive democracy, meritocracy is not a zero-sum competitive political system. Individualistic meritocracy emphasizes individual merits, while collectivistic meritocracy emphasizes the merit of the whole group. The purpose of meritocracy is to establish connective political infrastructure. China has practiced meritocracy for thousands years more or less continuously since then. In India, meritocracy extended to the life during continuous reincarnation. The inherent weakness of meritocracy is corruption for the lack of checks and balances from competition. The interdependent connective concrete political system is connective political professionalism.

For the economic systems in the East, the individualistic connective concrete economic system is individualistic connection economy which is practiced in Japan as reciprocal connection economy for keiretsu. Connection economy minimizes zero-sum competition. The collectivistic connective concrete economic 
system is collectivistic connection economy which is practiced in Japan as group connection economy for zaibatsu. Connection economy is in between capitalism and economic statism. It is less fragmented and fragile than capitalism, and more flexible and diverse than economic statism. The interdependent connective concrete economic system is connective economic professionalism among interdependent economic professions.

\subsubsection{Territorial Local Culture}

Territorial local culture appears in the prehistoric society, the society outside of extensive globalization, and the society that opposes globalization or the domination of hegemon. The individualistic-collectivistic territorial religions are individualistic-collectivistic local religions. The gods in local religions are typically local gods coexisting with other local gods in other local places. Historically, Judaism before the fall of Israel and Judah was largely a territorial local religion coexisting and mixing with other local religions. The interdependent territorial religion includes the prehistoric religion.

The individualistic-collectivistic territorial concrete political systems are individualistic-collectivistic territorialism. The territorialism for nation is nationalism. Individualistic nationalism is civil nationalism with geopolitical boundary. Collectivistic nationalism is ethnic nationalism with both geopolitical boundary and ethnic boundary, and all citizens in ethnic nationalism are united under one dominant ethnic group. Territorialism can also apply to a region, such as the Western Hemisphere's "Monroe Doctrine" that forbids military intervention from the countries outside of the Western Hemisphere.

The individualistic-collectivistic territorial concrete economic systems are individualistic-collectivistic protectionism with clear economic boundary. Individualistic protectionism is market protectionism, while collectivistic protectionism is state protectionism. The interdependent territorial political-economic systems are the interdependent territorial political-economic professionalism.

\subsection{The Cultures from Activity Social System Traits}

The 27 social systems from the combined sociality-worldview-awareness deal with different activities (mobilized and constructional). Every social system prepares people to mobilize in the case of natural destruction-renewal and dramatic downfall-rise. The sacred texts of the Western religions (Judaism, Christianity, and Islam) contain many prophesies and stories about natural destruction-renewal and dramatic downfall-rise, so the Western religions have the propensity for mobilized activity. The sacred texts of the Eastern religions (Hinduism, Confucianism, Buddhism, and Daoism) focus in the longevous world without end time, so Hinduism, Confucianism, Buddhism, and Daoism have the propensity for constructional activity. For the political and economic systems in the world of globalization and the domination of hegemons, it is difficult to maintain territorial worldview with clear boundary. Territorial worldview cannot exist easily for advanced countries. As a result, nationalism and protectionism can easily 
mobilize the devoted followers of territorial worldview.

\subsection{The Cultures from Legitimacy Social System Traits}

Different cultures under different times have different legitimacy social system traits. As described previously, the human cultural evolution in terms of authoritative legitimacy and rational legitimacy is through premodernity, modernity, and post modernity [4]. For animals and premodern humans, the source of legitimacy is authoritative legitimacy to follow tradition under homogeneous environment. Premodernity is authoritative local homogeneity. Under pluralistic environment, multiple well-established premodern authoritative traditions clashed, resulting in conflicting authoritative traditions in a region to generate chaotic regional diversity rejecting authoritative legitimacy. Modernity as rational regional diversity in a certain region replaced chaotic regional diversity through rational legitimacy. Modernity is rational regional diversity for the Eastern region and the Western region. According to Max Weber, modernity is directly related to rationality [31].

In the East, continuous modernity started in the Axial Age [32] from about $800 \mathrm{BC}$ to $200 \mathrm{BC}$ by Buddha, Confucius, and Laozi who went through the period of chaos due to conflicting authoritative traditions, and developed rational comprehensive systems without claiming themselves as the explicit representatives of authoritative gods. As a result, Confucianism, Daoism, and Buddhism are rational religions instead of authoritative religions. Under the influence of Buddha, rational Hinduism produced the Upanishads where the truth can be reached by a strictly personal effort in terms of knowledge. In the West, classical Greek philosophy by Socrates, Plato, and Aristotle during the Axial Age was also a rational system without relying on authoritative gods. A famous dictum from Socrates is "the unexamined life is not worth living". However, in the West, the modernity started by classical Greek philosophy was intermittent instead of continuous until the Renaissance when Rene Descartes (1596-1650) promoted independent reason (I think, therefore I am) instead of authoritative tradition as the starting point of knowledge. Freeing people from the restriction of authoritative tradition and bringing rational order to the chaotic society, modernity expanded civilization and wealth. Since India and China started continuous modernity thousands years earlier than the West, they were the wealthiest countries for thousands years before the Industrial Revolution.

The Industrial Revolution and the Information Revolution have spread throughout the world. The world is increasingly affluent, interdependent, and diverse. Today, very few products are manufactured entirely in a single country, and people consume products daily from all over the world. The Industrial and Information Revolutions have produced pluralistic global society under different social system traits from the West and the East, resulting in the clash of conflicting social system traits to generate chaotic global diversity that questions and rejects the legitimacy of modernity as rational regional diversity. Like modernity 
as rational regional diversity to replace chaotic regional diversity, postmodernity as rational global diversity will replace current chaotic global diversity. Like modernity, postmodernity will bring peace and order to the world. To reach postmodernity as rational global diversity, the seven maladaptive obstacles need to be replaced by the seven adaptive rational systems as follows.

\subsubsection{The Maladaptive Denial of Rational Global Diversity}

The first obstacle is the maladaptive denial of rational global diversity. Some people simply deny rational global diversity for the diverse world. It is unfortunate, because we have already lived in highly mixed social systems. In the West, Confucian meritocracy began its popularity in Europe in the $19^{\text {th }}$ century, so to improve the quality of civil service, Europe and America introduced merit-based civil services. Since then, the European and American political systems have been essentially liberal merito-democracy. Different countries have different degrees of meritocracy. The West typically practices the mixed economy as an economic system combining private capitalism and public economic statism. Different countries have different degrees of capitalism and statism. Through mixed social systems, the weaknesses of pure social systems are minimized.

A proper way to understand rational global diversity is the rational big five social system traits. All social systems in the big five social system traits are orderly under proper social conditions. Some social systems are adaptive to the prevailing social condition of the world which is increasingly affluent, interdependent, and diverse, while other social systems are maladaptive. The denial of rational global diversity prevents the adoption of adaptive social systems. The maladaptive denial of rational global diversity needs to be replaced by the adaptive rational acceptance of rational global diversity through the rational social systems, such as the big five social system traits.

\subsubsection{The Maladaptive Sectarian Social Group Deviances}

The behaviors of some groups are the obstacle to postmodernity, and such behaviors are social group deviances. Social group deviance is characterized by enduring maladaptive deviant patterns of behavior of social group deviating from prevailing normal culture [33]. Therefore, different prevailing cultures produce different social group deviances. Social group deviances from deviant social group and personality disorders from disordered person are similar. These deviances have futile deviances and recklessness deviances as described in Section 2.3. The social system traits in futile social group deviances are in extreme confrontations against the opposite social system traits which prevail culturally. The prevailing culture of the current world is the increasingly affluent, interdependent, and diverse world. As a result, the prevailing social systems traits are concrete awareness trait for concrete industrial-information technologies and science to achieve affluence, constructional activity trait for longevous world without major war among interdependent major powers for a long time, and rational legitimacy trait to accommodate the diversity in the diverse world. As the 
oppositions to the prevailing social system traits, the subservient social system traits for social group deviances are imaginary awareness trait resulted from stress-trauma, mobilized activity trait resulted from the perceived danger of downfall, and authoritative legitimacy trait resulted from the absence of workable rational legitimacy trait among conflicting authoritative traditions. The extreme confrontations to prevailing culture produce the same deviances as personality disorders in Table 3. In Western culture, all major Western religions follow mostly authoritative legitimacy trait. From Table 3, the combination of maladaptive deviances from odd-eccentric, dramatic-impulsive, and anxious-fearful clusters produce "sectarian social group deviances" consisting of agreeable (sociable and inoffensive) schizotypal-histrionic-dependent for charismatic fundamentalism [34], disagreeable (sociable and offensive) paranoid-antisocialborderline-obsessive-compulsive for illusory fanaticism [35], and isolating (unsociable and inoffensive) schizoid-narcissistic-avoidant for mystical cultism. These maladaptive sectarian social group deviances need to be replaced by adaptive workable mainstream religions under peaceful religious, political, and economic conditions. The mainstream religions must actively and strongly advocate love and peace in religions, actively and strongly denounce extremism, bigotry, hate, and violence in sectarian social group deviances as religious heresies.

\subsubsection{The Maladaptive Secular Social Group Deviances}

Social group deviances can also occur in secular realm. The origin of religion with imaginary awareness is vulnerable people reaching out to the imaginary supernatural for help during the harsh Upper Paleolithic Period. Each group of the believers in the supernatural develops its supernatural world and supernatural connection. The origin of modern science is devout religious people reaching out to nature and rationality for the understanding of imaginary supernatural during the Renaissance-Enlightenment. Most early major scientists were devout Christians. Originally, scientists developed the scientific world and connection involving the supernatural. Subsequently, scientists moved away from their origin. Deist scientists develop the scientific world for the supernatural without the scientific connection with the supernatural. Atheist scientists develop the scientific world without the supernatural, resulting in the conflict between religion and science. Extreme anti-religion emerges. In Western culture, anti-religion is anti-authoritative legitimacy trait, because major Western religions are mostly authoritative. From Table 3, the combination of the deviances from odd-eccentric, dramatic-impulsive, and doubtful-prying clusters produce "secular social group deviances" consisting of agreeable (sociable and inoffensive) schizotypal-histrionic-anarchic for humanistic anarchism [36], disagreeable (sociable and offensive) paranoid-antisocial-borderline-quarrelsome for sacrilegious skepticism [37], and isolating (unsociable and inoffensive) schizoid-narcissisticevasive for egotistic agnosticism. In Western culture, secular social group deviances (humanistic anarchism, sacrilegious skepticism, and egotistic agnosticism) clash fiercely with sectarian social group deviances (charismatic fundamentalism, 
illusory fanaticism, and mystical cultism).

Gradually, scientists have moved away from the denial of the supernatural. Science cannot deny vulnerable people reaching out to the supernatural for help [38]. Albert Einstein said, "Science without religion is lame, religion without science is blind." Scientist cannot totally deny the supernatural world and connection involving the supernatural, because scientists have no definite answer for the seemingly purposeful universe to facilitate the existence of humans. As a result, the conflict between religion and science can be replaced by rational agreement, such as the rational trinity consisting of the unknowable transcendental source, the knowable immanent source, and the imaginary source, corresponding roughly to the Father, the Son, and the Holy Spirit, respectively, in Christian theology of trinity [4]. The transcendental source is the unknowable transcending nature. In religion, such source is the unseen sacred supernatural as described in the Bible, "No one has ever seen God. (John 1: 8)". Science will also eventually reach the realm which is unknowable, corresponding to the nameless as described in the first chapter of Dao De Jing: "the name that can be named is not the eternal name; the nameless is the origin of Heaven and Earth". The immanent source is the knowable to the believers of the supernatural through their supernatural worlds and supernatural connections, and the knowable to scientists through the seemingly purposeful universe as expressed in the anthropic principle of cosmology [39] and the simulation hypothesis of cosmology [40] to facilitate the existence of humans. Imagination is the foundation of both religion proposed by Maurice Bloch [21] and fundamental science, such as quantum physics and cosmology based on imagination very different from ordinary perception. The maladaptive conflict between religion and science and secular social group deviances need to be replaced by the adaptive rational trinity reflecting the three sources in both religion and science. Through the rational trinity, science and religion find the common ground to facilitate the wellbeing of human existence.

\subsubsection{The Maladaptive Domination of Global Hegemons}

The domination of global hegemons derived from competitive worldview is a maladaptive obstacle to post modernity as rational global diversity, because global hegemons intend to impose their powers and social systems in other countries to destroy the diversity in the diverse world. Furthermore, in the increasingly affluent, interdependent, and diverse world, the domination of global hegemons becomes increasingly impossible, pointless, and dangerous. Realistically, no global hegemon can religiously, politically, and economically dominate the diverse world. In the interdependent world where all nations are interdependent, it is pointless to be the global hegemon to dominate the interdependent world. The tremendous destructive military power of global hegemons makes the conflict among global hegemons to dominate the world very dangerous. The dangerous proxy wars supported by global hegemons unfairly create tremendous destructions and international conflicts to the areas far away from the global 
hegemons.

As described in the previous paper [4], to preserve diversity, the maladaptive domination of global hegemons needs to be replaced by the adaptive rational "World Regional Community Organization" where every country in the world belongs to one of 12 regional communities with cultural-geographic boundaries. Many such regional communities exist already. Each regional community in World Regional Community Organization has at least one economically large country to support its regional community. The embryo of the World Regional Community Organization can be found in the BRICS for Brazil, Russia, India, China and South Africa as the largest countries and the cornerstones in the five of the 12 regional communities. The BRICS can be expanded to include all 12 cornerstones. Each regional community imposes "Monroe Doctrine" that forbids military intervention from the countries outside of the regional community, except the intervention approved by the United Nations. As a result, all overseas military bases as the military intrusion from the countries outside of a regional community have to be abolished. All military defense treaties connected to the countries outside of a regional community have to be ended. Through the adaptive rational World Regional Community Organization, peace and diversity instead of wars and global hegemons prevail.

\subsubsection{The Maladaptive Militarized Offensive Foreign Policy}

Each of competitive, connective, and territorial worldviews develops its foreign policy [4]. As pointed out by John Mearsheimer, competitive worldview in competitive Western culture has militarized offensive foreign policy derived from offensive realism [41]. Numerous military alliances are the foundations of militarized offensive foreign policy. As pointed out in the previous paper [4], connective worldview develops infrastructural foreign policy derived from infrastructural realism for the infrastructure in international trade. The recent One Belt, One Road (OBOR) is an example of infrastructural foreign policy. Territorial worldview develops territorial foreign policy derived from territorial national-regional realism. All nations enforce national territorial foreign policy. Some regions enforce regional territorial foreign policy, such as the Western Hemisphere's "Monroe Doctrine" that forbids military intervention from the countries outside of the Western Hemisphere.

As pointed out by John Mearsheimer, militarized offensive foreign policy involves inevitably and tragically wars and conflicts as described in John Mearsheimer's “The Tragedy of Great Power Politics" [41]. Such destructive maladaptive militarized offensive foreign policy needs to be replaced by adaptive infrastructural foreign policy and regional territorial foreign policy. In infrastructural foreign policy, nations build infrastructures to connect nations together, resulting in increasing economic and cultural interdependence among nations. Regional territorial foreign policy provides the base for the World Regional Community Organization. Adaptive infrastructural foreign policy and regional territorial foreign policy make maladaptive militarized offensive foreign policy 
unnecessary. All offensive weapons, such as intercontinental ballistic missiles, long-distant offensive nuclear aircraft carriers and submarines, nuclear weapons, and stealth aircrafts have to be abolished. Only weapons allowed are short-distant, non-nuclear, and non-stealth defensive weapons. Without large military expense in overseas military bases and offensive weapons, the military spending for each country is set to reduce to maximum $2 \%$ of GDP and then for further reduction like the gradual reduction of tariff by the WTO (World Trade Organization). Through infrastructural and regional territorial foreign policies to replace militarized offensive foreign policy, peace, prosperity, and order prevail.

\subsubsection{The Maladaptive Conflicting International Trade}

International trade is a contentious issue. Different worldviews develop different international trades [4]. Competitive, connective, and territorial worldviews develop free competitive, free connective, and fair protectionist international trades, respectively. Free competitive international trade benefits trading countries where each country develops its own "trade specialty" with comparative advantage in international trade. Free competitive international trade provides robust economic growth and economic specialty. Free connective international trade benefits trading countries where connective infrastructure is the primary trade. Infrastructure is the backbone of connectivity which is lifeblood of commerce today. Protectionism derived from territorial worldview includes protectionism to protect trade specialty and protectionism to protect trade non-specialty outside of trade specialty. Free connective and fair protectionism international trades provide economic diversity and stability. The maladaptive conflicting international trades among competitive, connective, and protectionist international trades needs to be replaced by the adaptive rational trichotomic international trade containing free competitive, free connective, and fair protectionist international trades to have the balance of economic specialty and diversity for economic growth and stability [4]. Most of such trichotomic international trade has been practiced in the WTO.

\subsubsection{The Maladaptive Denial of Climate Change}

Climate change is a change in climate patterns which are attributed largely to the increased levels of atmospheric carbon dioxide produced by the human use of fossil fuels as the major energy source in the last few decades. In many parts of the world, climate change has caused increasingly severe damages from flood, drought, forest fire, coast flooding, the rise of sea level, and increasingly destructive typhoons and hurricanes. If continue to deny climate change for longer term, the damages will be devastating to human society. Such maladaptive denial of climate change is a maladaptive obstacle to reach post modernity. The maladaptive denial of climate change needs to be replaced by the adaptive Paris climate agreement which was signed by almost all countries in the world in 2015 to recognize and mitigate climate change. The Agreement is to work towards a long-term goal of keeping the increase in global average temperature to well below 
$2^{\circ} \mathrm{C}$ above pre-industrial levels, ideally aiming to limit the increase to $1.5^{\circ} \mathrm{C}$. The Agreement will minimize the damage from climate change in future post modernity.

\section{Summary and Conclusion}

In summary, this paper proposes the big five social system traits as the fixed, clear, and workable social solutions to the social issues under the different social conditions. Under the big five social system traits, different fixed and clear personal behaviors are developed by different people under different social conditions, so the big five social system traits are the source of the different aspects of human behavior in terms of the personality traits in the big five personality traits, the personality types in the MBTI, the social styles in the social style model, the personality disorders in the DSM-5, and religious, political, and economic systems in cultures.

The big five social system traits consist of sociality (individualistic, collectivistic, or interdependent) to the issue of social formation (under allies, friends, or intimates), worldview (connective-competitive-territorial or people-tasks) to the issue of social boundary (under ingroup, outgroup, or ingroup-outgroup), awareness (concrete or imaginary) to the issue of social stress (under stress-free or stressful), activity (constructional or mobilized) to the issue of social duration (under longevity or transience), and legitimacy (authoritative rational) to the issue of social uniformity (under homogeneity or pluralism).

In the big five personality traits, extraversion as relentless and forceful attention to relationship is derived from individualistic sociality trait in the social system of allies with changeable social bonds, while introversion as timely and moderate attention to relationship results from collectivistic sociality trait and interdependent sociality trait in the social systems of friends and intimates with stable social bonds. In the big five personality traits, agreeableness, disagreeableness, and isolation are derived from connective, zero-sum competitive, and territorial worldviews traits, respectively in the social systems of ingroup, outgroup, and ingroup-outgroup, respectively. In the big five personality traits, neuroticism is derived from imaginary awareness trait in stressful social system that generates permanent imaginary thoughts, while calmness results from concrete awareness trait in stress-free social system. In the big five personality traits, conscientiousness as broad deliberation is derived from constructional activity trait in longevous social system, while impulsiveness as narrow deliberation results from mobilized activity trait in transient social system. In the big five personality traits, openness to experience to question all traditions is derived from rational legitimacy trait to accommodate diverse pluralistic social system, while closeness to experience to obey all traditions results from authoritative legitimacy trait to accommodate homogeneous social system.

Extraversion-introversion in the MBTI is derived from individualisticcollectivistic sociality from social system traits, feeling-thinking from people-tasks 
worldview, perceiving-judging from mobilized-constructional activity, and sensing-intuition from authoritative-rational legitimacy. Tell-ask and people-tasks in the social style model are derived from individualistic-collectivistic sociality and people-tasks worldview, respectively in social system traits. Odd-eccentric, dramatic-impulsive, and anxious-fearful clusters in the DSM-5 personality disorders and doubtful-prying cluster are derived from the extremely adverse conditions without workable imaginary awareness, mobilized activity, authoritative legitimacy, and rational legitimacy, respectively. Personality disorders are also derived from the personality traits under the extreme confrontations against their opposite personality traits which prevail culturally. Sectarian social group deviances (charismatic fundamentalism, illusory fanaticism, and mystical cultism) and secular social group deviances (humanistic anarchism, sacrilegious skepticism, and egotistic agnosticism) can be derived from the DSM-5 and the big five social system traits.

Competitive Western culture includes concrete individualistic democracy-capitalism, concrete collectivistic statism, and imaginary Judaism-IslamChristianity. Connective Eastern culture includes concrete meritocracy, concrete connection economy, and imaginary Hinduism-Confucianism-Buddhism-Daoism. All cultures involve different activities and legitimacies. The human cultural evolution in terms of authoritative legitimacy and rational legitimacy is through premodernity, modernity, and postmodernity. To reach postmodernity as rational global diversity, the seven maladaptive obstacles (maladaptive denial of rational global diversity, sectarian social group deviances, secular social group deviances, domination of global hegemons, militarized offensive foreign policy, conflicting international trade, and denial of climate change) need to be replaced by the seven adaptive systems.

The result is that different aspects of human behavior in terms of social system traits, personality traits, personality disorders, social group deviances, religion, politics, and economy are unified by the big five social system traits, resulting in the unified theory of human behavior based on the big five social system traits. The unified theory of human behavior provides the common ground to describe different aspects of human behavior. For examples, Christianity in terms of the big five social system traits has interdependent sociality, competitive worldview, imaginary awareness, mobilized activity for transient society, and authoritative legitimacy. Based on such social system, Christianity in terms of the big five personality traits has introversion, disagreeableness, neuroticism, impulsiveness, and closeness to experience. Christianity in terms of personality disorders overcomes odd-eccentric cluster through the workable imaginary awareness of personal God, overcomes dramatic-impulsive cluster through the workable mobilized activity of Jesus' resurrection (dramatic downfall-rise), and overcomes fearful-anxiety cluster through the workable authoritative legitimacy of the Bible. Christianity in terms of social group deviances has to overcome unworkable charismatic fundamentalism, illusory fanaticism, and mystical 
cultism. Confucianism in terms of the big five social system traits has individualistic-collectivistic sociality, connective worldview, imaginary awareness, constructional activity for longevous society, and rational legitimacy. Confucianism in terms of the big five personality traits has extraversion-introversion, agreeableness, neuroticism, conscientiousness, and openness to experience. Confucianism in terms of personality disorders overcomes odd-eccentric cluster through the workable imaginary awareness of impersonal heaven, and overcomes doubtful-prying cluster through the workable rational legitimacy of comprehensive reciprocal relations and familial model. As a way of life derived from classical Greek philosophy, science in terms of social system traits has individualistic sociality, task worldview, concrete awareness, constructional activity, and rational legitimacy. Science in terms personality traits has extraversion, disagreeableness, calmness, conscientiousness, and openness to experience. Science in term of personality disorders overcomes doubtful-prying cluster through the rational legitimacy of scientific unified theories. Science in terms of social group deviances has to overcome unworkable humanistic anarchism, sacrilegious skepticism, and egotistic agnosticism. As a result, through the unified theory of human behavior, Christianity, Confucianism, and other major religions become imaginary therapies for personality disorders and social group deviances, while science becomes the concrete therapy. At the same time, the unified theory of human behavior provides the common ground for the communication among all major religions and science.

Capitalism in terms of the big five social system traits has individualistic sociality, competitive worldview, concrete awareness, constructional activity, and openness to experience. Capitalism in terms of the big five personality traits has extraversion, disagreeableness, calmness, conscientiousness, and openness to experience. Capitalism in terms of personality disorders overcomes doubtful-prying cluster through the rational legitimacy of rational free market. Liberal democracy for politics is similar to capitalism for economy. Meritocracy in terms of social system traits has individualistic-collectivistic sociality, connective worldview, concrete awareness, constructional activity, and openness to experience. Meritocracy in terms of personality traits has extraversion-introversion, agreeableness, conscientiousness, and openness to experience. Meritocracy in terms of personality disorders overcomes doubtful-prying cluster through rational legitimacy of comprehensive merited based bureaucracy. Through the unified theory of human behavior, political and economic systems can be classified by personality traits and personality disorders. In conclusion, the big five social system traits provide the base for the unified theory of human behavior to unify different aspects of human behavior and to produce the common ground for diverse views to communicate.

\section{References}

[1] Parsons, T. (1951) The Social System. The Free Press, New York.

[2] Chung, D. (2016) The Basic Principles of Kin Sociality and Eusociality: Human 
Evolution. Natural Science, 8, 8-19. https://doi.org/10.4236/ns.2016.81002

[3] Chung, D. (2016) The Human Religious Evolution. Open Journal of Social Sciences, 4, 75-90.

[4] Chung, D. (2017) Human Cultural Evolution: Postmodernity as Rational Global Diversity. Open Journal of Social Sciences, 5, 304-337. https://doi.org/10.4236/jss.2017.55022

[5] McDonald, M. (2012) Evolution and the Psychology of Intergroup Conflict: The Male Warrior Hypothesis. Personality and Social Psychology Bulletin, 32, 1559-1572. https://doi.org/10.1098/rstb.2011.0301

[6] Goldberg, L. (1993) The Structure of Phenotypic Personality Traits. American Psychologist, 48, 26-34. https://doi.org/10.1037/0003-066X.48.1.26

[7] Myers, I. and Myers, P. (1995) Gifts Differing: Understanding Personality Type. Davies-Black Publishing, Mountain View.

[8] Merrill, D. and Reid, R. (1999) Personal Styles and Effective Performance. CRC Press, New York.

[9] Costa, P. and Widiger, T. (1994) Personality Disorders and the Five-Factor Model of Personality. American Psychological Association, Washington DC. https://doi.org/10.1037/10140-000

[10] American Psychiatric Association (2013) Diagnostic and Statistical Manual of Mental Disorders. 5th Edition, American Psychiatric Publishing, Arlington.

[11] Hamilton, W. (1964) The Genetical Evolution of Social Behavior II. Journal of Theoretical Biology, 7, 17-52.

[12] Crespi, B.J. and Douglas, Y. (1995) The Definition of Eusociality. Behavior Ecology, 6, 109-115. https://doi.org/10.1093/beheco/6.1.109

[13] Wilson, E. (2012) The Social Conquest of the Earth. W. W. Norton \& Company, New York

[14] McCrae, R. and Terracciano, A. (2005) Personality Profiles of Cultures: Aggregate Personality Traits. Journal of Personality and Social Psychology, 89, 407-425. https://doi.org/10.1037/0022-3514.89.3.407

[15] Turner, J.C. and Reynolds, K.J. (2010) The Story of Social Identity. In: Postmes, T. and Branscombe, N., Eds., Rediscovering Social Identity: Core Sources, Psychology Press, New York.

[16] Cohen, T., Montoya, R. and Insko, C. (2006) Group Morality and Intergroup Relations: Cross-Cultural and Experimental Evidence. Personality and Social Psychology Bulletin, 32, 1559-1572. https://doi.org/10.1177/0146167206291673

[17] Shultz, T., Hartshorn, M. and Kaznatcheev, A. (2009) Why Is Ethnocentrism More Common than Humanitarianism? Proceedings of the 31 st Annual Conference of the Cognitive Science Society 2010-2015.

[18] Dixson, A. and Dixson, B. (2011) Venus Figurines of the European Paleolithic: Symbols of Fertility or Attractiveness? Journal of Anthropology, 2011, Article ID: 569120. https://doi.org/10.1155/2011/569120

[19] Lewis-Williams, D. (2002) The Mind in the Cave: Consciousness and the Origins of Art. Thames \& Hudson, London.

[20] Higham, T. (2014) The Timing and Spatiotemporal Patterning of Neanderthal Disappearance. Nature, 512, 306-309.

[21] Bloch, M. (2006) Why Religion Is Nothing Special but Is Central. Philosophical Transactions of the Royal Society B, 363, 1499.

https://doi.org/10.1098/rstb.2008.0007 
[22] Taylor, M. (1999) Imaginary Companions and the Children Who Create Them. Oxford University Press, New York.

[23] Taylor, M., Hulette, A. and Dishion, T. (2010) Longitudinal Outcomes of Young High-Risk Adolescents with Imaginary Companions. Developmental Psychology, 46, 1632-1636. https://doi.org/10.1037/a0019815

[24] Angus, D., et al. (2015) Limitations in Social Anticipation Are Independent of Imaginative and Theory of Mind Abilities in Children with Autism but Not in Typically Developing Children. Autism, 19, 604-612.

[25] Furnham, A., Moutafi, J. and Crump, J. (2003) The Relationship between the Revised Neo-Personality Inventory and the Myers-Briggs Type Indicator. Social Behavior and Personality, 31, 577-584. https://doi.org/10.2224/sbp.2003.31.6.577

[26] Ajnakina, O., et al. (2016) Impact of Childhood Adversities on Specific Symptom Dimensions in First-Episode Psychosis. Psychological Medicine, 46, 317-326. https://doi.org/10.1017/S0033291715001816

[27] Wingenfeld, K., Spitzer, C., Rulkotter, N. and Lowe, B. (2010) Borderline Personality Disorder: Hypothalamus Pituitary Adrenal Axis and Findings from Neuroimaging Studies. Psychoneuroendocrinology, 35, 154-170.

[28] Karlberg, M. (2004) Beyond the Culture of Contest: From Adversarialism to Mutualism in an Age of Interdependence. George Ronald Publisher, Welwyn.

[29] Lessig, L. (2011) Republic, Lost: How Money Corrupts Congress. Twelve, New York.

[30] Talhelm, T. (2014) Large-Scale Psychological Differences within China Explained by Rice versus Wheat Agriculture. Science, 9, 603-608. https://doi.org/10.1126/science.1246850

[31] Larraín, J. (2001) Identity and Modernity in Latin America. Blackwell Publishing, Malden.

[32] Armstrong, K. (2006) The Great Transformation: The Beginning of Our Religious Traditions. Knopf, New York.

[33] Becker, H. (1963) Outsiders: Studies in the Sociology of Deviance. The Free Press, New York.

[34] Lehmann, D. and Iqtidar, H. (2011) Fundamentalism and Charismatic Movements. Routledge, London.

[35] Haynal, A., Molnar, M. and de Puymege, G. (1987) Fanaticism: A Historical and Psychoanalytical Study. Schoken Books, New York.

[36] Call, L. (2002) Postmodern Anarchism. Lexington Books, Lexington.

[37] Bruno, A. and Rutherford, A. (2017) Skepticism: Historical and Contemporary Inquiries. Routledge, London.

[38] De Botton, A. (2012) Religion for Atheists: A Non-believer's Guide to the Uses of Religion. Hamish Hamilton, London.

[39] Mosterín, J. (2005) Antropic Explanations in Cosmology. In: Hajek, V. and Westerstahl, Eds., Proceedings of the 12 th International Congress of Logic, Methodology and Philosophy of Science.

[40] Bostrom, N. (2003) Are You Living in a Simulation? Philosophical Quarterly, 53, 243-255. https://doi.org/10.1111/1467-9213.00309

[41] Mearsheimer, J. (2001) The Tragedy of Great Power Politics. W.W. Norton \& Company, New York. 
Submit or recommend next manuscript to SCIRP and we will provide best service for you:

Accepting pre-submission inquiries through Email, Facebook, LinkedIn, Twitter, etc. A wide selection of journals (inclusive of 9 subjects, more than 200 journals)

Providing 24-hour high-quality service

User-friendly online submission system

Fair and swift peer-review system

Efficient typesetting and proofreading procedure

Display of the result of downloads and visits, as well as the number of cited articles Maximum dissemination of your research work

Submit your manuscript at: http://papersubmission.scirp.org/

Or contact jss@scirp.org 